\title{
Utility of uterine artery Doppler and pulsatility index at 11-14 weeks of normal pregnancy in prediction of preeclampsia in third trimester
}

\author{
Bindal $\mathbf{J}^{1}$, Chugh $\mathbf{N}^{2}$ \\ ${ }^{1}$ Dr Jyoti Bindal Professor \& Head, Department of Obstetrics \& Gynaecology, ${ }^{2}$ Dr Niketa Chugh, Ex Resident, \\ Department of Obstetrics \& Gynaecology. Both affiliated with G R Medical College, Gwalior, MP, India.
}

Address for Correspondece: Dr Jyoti Bindal, JAH Campus, G R Medical College, Gwalior, MP, India. drjyotibindal@bindal.me

\begin{abstract}
Introduction: Preeclampsia affects 5-8\% of women in pregnancy and leading cause of maternal mortality. The present study was done to predict the development of preeclampsia in patients with uterine artery pulsatility index $(\mathrm{PI})>1.71$ and the presence of diastolic notch at 11-14 weeks of gestation belonging to low risk population. Methods: Women attending routine antenatal care were offered an early transvaginal ultrasound scan between 11-14 weeks including uterine artery doppler assessment. Mean PI and presence or absence of bilateral early diastolic notch was also noted. All patients were followed up to term for the development of preeclampsia. Results: Out of 100 patients, 22\% developed preeclampsia of which $15(68.18 \%)$ cases showed the presence of diastolic notch and $12(54.54 \%)$ cases had PI $>1.71(p<0.05)$. A Total of $12 \%$ of patients showed presence of both diastolic notch and PI of $>1.71(\mathrm{p}<0.05)$. Out of 37 nulliparous patients 13 $(35.13 \%)$ developed preeclampsia, $8(13.79 \%)$ out of 58 primiparous and $1(20 \%)$ out of 5 multipara developed preeclampsia $(\mathrm{p}<0.05)$. All 11 patients with systolic blood pressure $>140 \mathrm{~mm}$ of $\mathrm{Hg}$ at $11-14$ weeks of gestation developed preeclampsia $(\mathrm{p}<0.05)$. Conclusion: Presence of diastolic notch and PI of $>1.71$ in uterine artery colour doppler at 11-14 weeks of gestation serves as a good predictor of preeclampsia at term, in pregnancies with no other associated risk factors.
\end{abstract}

Key Words: Pulsatility index, Preeclampsia, Diastolic notch

\section{Introduction}

Hypertensive disorders and their associated complications are responsible for a significant proportion of perinatal and maternal morbidity and mortality during pregnancy. Although the exact aetiology of this range of disorders is unknown and very likely multi-factorial, several lines of evidence suggest a common base in abnormal placentation and impaired perfusion in all [1].

Indeed there is extensive evidence that uterine artery Doppler ultrasound constitutes a useful non-invasive method to assess utero-placental perfusion and to predict further development of preeclampsia, fetal growth restriction, placental abruption and stillbirth [2].

Manuscript received: $7^{\text {th }}$ Feb 2016

Reviewed: $15^{\text {th }}$ Feb 2016

Author Corrected: $25^{\text {th }}$ Feb 2016

Accepted for Publication: $13^{\text {th }}$ March 2016
There is some evidence that the identification of at risk population in the first and early second trimesters of pregnancy would allow the investigation of the possible effects of different prophylactic strategies [3].

Diastolic notch is small dip (usually found during 12-14 weeks of gestation) found just before the diastolic wave begins. It suggests that process is ongoing [4].

The majority of research has been cantered on an elevation in the pulsatility index or the persistence of a uterine artery diastolic notch to detect the presence of increased utero-placental vascular resistance [4].

It has been suggested by many studies that uterine artery Doppler at 12-16 weeks of gestation are very useful to identifying risk of pre-eclampsia $[3,5]$. One study evaluated its utility in third-trimester to predict 
hemodynamic deterioration and adverse perinatal outcome [6].

The Gomez et al evaluated the uterine artery PI value in the first trimester and were able to identify $30.8 \%$ of pregnancies that subsequently developed severe pregnancy complications by using the 90th percentile as the cut-off [7].

In the present study, uterine artery colour doppler and PI values along with presence of diastolic notch was studied at 11-14 weeks of gestation in normal pregnancy and assessed as a predictor of preeclampsia at term.

\section{Method}

A hospital based prospective study was carried out on 100 patients at the Department of Obstetrics and Gyneacology, Kamla Raja Hospital, Gwalior over a period of one year from November 2013 to October 2014. A written informed consent from all the patients and Ethical Committee approval was obtained before starting the study.

All women attending routine antenatal care with a singleton pregnancy at 11-14 weeks of gestation were included in the present study. Patients with history of essential hypertension, history of preeclampsia in previous pregnancy, history of treatment with aspirin and heparin or anti-hypertensive drugs were excluded from the study.

All patients underwent an early transvaginal ultrasound including uterine artery Doppler and PI values of both uterine arteries were calculated. The presence or absence of early diastolic notch was also noted. These patients were followed up to the term for development of preeclampsia.

All the data were analyzed using IBM SPSS- ver.20 software. Analysis was performed using chi-square test and independent sample student $\mathrm{t}$ test. $\mathrm{P}$ values $<0.05$ was considered to be significant.

\section{Result}

Out of 100 patients, most of the patients belong to the age group of 21-30 (52\%) years, about half of the patients had secondary education (49\%), and belong to socioeconomic status class $3(45 \%)$, most of them were having single parity $(58 \%)$ and maximum patients had gestational age of more than 38 weeks (Table 1).

Table-1: Distribution of patients according to different characteristic of patients

\begin{tabular}{|c|c|c|c|c|}
\hline \multicolumn{2}{|c|}{ Parameters } & No of Patients & Preeclampsia* & Non-Preeclampsia* \\
\hline \multirow{3}{*}{ Age (years) $)^{\#}$} & $\leq 20$ & 46 & $11(23.9)$ & $35(76)$ \\
\hline & $21-30$ & 52 & $10(19.2)$ & $42((80)$ \\
\hline & $>30$ & 2 & $1(50)$ & $1(50)$ \\
\hline \multirow{4}{*}{ Education@ } & Primary & 11 & $1(9)$ & $10(90.9)$ \\
\hline & Secondary & 49 & $17(34.6)$ & $32(65.3)$ \\
\hline & Intermediate & 38 & $4(10.5)$ & $34(89.4)$ \\
\hline & Graduation & 2 & $0(0)$ & $2(100)$ \\
\hline \multirow{4}{*}{$\begin{array}{l}\text { Socioeconomic } \\
\text { Status }{ }^{\#}\end{array}$} & 2 & 3 & $0(0)$ & $3(100)$ \\
\hline & 3 & 45 & $9(20)$ & $36(80)$ \\
\hline & 4 & 32 & $8(25)$ & $24(75)$ \\
\hline & 5 & 20 & $5(25)$ & $15(75)$ \\
\hline \multirow{3}{*}{ Parity ${ }^{@}$} & 0 & 37 & $13(35.2)$ & $24(64.8)$ \\
\hline & 1 & 58 & $8(13.7)$ & $50(86.2)$ \\
\hline & 2 & 5 & $1(20)$ & $4(80)$ \\
\hline \multirow{4}{*}{$\begin{array}{l}\text { Gestational age } \\
\text { (weeks) }\end{array}$} & $>38$ & 62 & $2(3.2)$ & $60(96.7)$ \\
\hline & $36-38$ & 28 & $14(50)$ & $14(50)$ \\
\hline & $34-36$ & 4 & $4(100)$ & $0(0)$ \\
\hline & $32-34$ & 5 & $2(40)$ & $3(60)$ \\
\hline
\end{tabular}

*Data are expressed as no of patients $(\%),{ }^{*} \mathrm{P}>0.05,{ }^{@}(\mathrm{p}<0.05)$ 
BP at 11-14 weeks of gestation showed that $83 \%$ had SBP of $<130 \mathrm{~mm} \mathrm{Hg}$, out of which 6 (7.22\%) developed preeclampsia, 6\% patients had SBP between 130-139 mm Hg, out of which $5(83.3 \%)$ had developed preeclampsia and all $5 \%$ patients who had SBP $>150 \mathrm{mmHg}$ developed preeclampsia $(\mathrm{p}=0.001)$. All $22 \%$ patients who had diastolic blood pressure between 90-100 mm Hg during 11-14 weeks of gestation developed preeclampsia. Out of 35 patients, who had diastolic notching at 11-14 weeks, 15 (42.8\%) patients had preeclampsia, whereas out of 65 patients who had no diastolic notch at 11-14 weeks of gestation, preeclampsia was noted in $7(10.7 \%)$ patients $(\mathrm{p}<0.05)$.

Patients developing preeclampsia (12 cases) were found to have pulsatility index $>1.71$ making the association statistically significant. $(\mathrm{p}=0.001)$.

In presence of diastolic notch, 57.14\% patients who developed preeclampsia had pulsatility index $>1.71$ while $22.22 \%$ patients who developed preeclampsia had pulsatility index $<1.71$, hence making the association statistically significant $(\mathrm{p}=0.027)$.

\section{Discussion}

We tried to find, whether uterine artery Doppler measurements made between 11-14 weeks of gestation would predict the subsequent development of preeclampsia.

Out of 100 women studied $22 \%$ developed preeclampsia making the prevalence almost similar to previous studies $(31.42 \%)$ [8].

In present study, there was no association between preeclampsia and the age of women $(p=0.536)$. Similar results were reported by Kiondo et al $(p=0.33)$ [9].

Most of the patients (49\%) had secondary education, of which, 17 (34.69\%) had preeclampsia and no patients was graduate. In present study there was a significant association between educational status and development of preeclampsia $(p=0.027)$. Dinglas et al has also reported significant relationship between education level and development of signs and symptoms of preeclampsia $\left(\mathrm{X}^{2}=9.059, \mathrm{p}\right.$ value $\left.=0.018\right)[10]$. Mothers with no education were about seven times more likely to have all six signs and symptoms of preeclampsia than those with seven or more years of education [10]. Kiondo et al showed discordant results where he found no such relation between patient's education and development of preeclampsia $(p=0.135)$ [9].

Most of the patients (45\%) belong to socioeconomic class 3 as per the Modified B.G. Prasad classification [11]. Out of that, $9(20 \%)$ patients developed preeclampsia. None of the patients belonging to socioeconomic class 2 developed preeclampsia. There was no correlation between socioeconomic class and development of preeclampsia $(\mathrm{p}=0.747)$ Similar findings has been reported by other workers also [9].
Lindsay et al in their study however found that low maternal socioeconomic status was a strong risk factor for development of preeclampsia [12].

Out of 37 nulliparous patients, 13 (35.13\%) developed preeclampsia which was significant $(\mathrm{p}<0.05)$. Out of 58 primiparous patients, $8 \quad(13.79 \%)$ developed preeclampsia $(p=0.04)$. Similar results were seen in study by Long et al, they reported preeclampsia incidence of $9.3 \%$, being significantly higher in primipara $(14.1 \%)$ than multipara $(5.7 \%)(\mathrm{p}<0.001)$ [13]. Kiondo et al also reported that primigravidae were three times more likely to develop pre-eclampsia than women who were gravida $2-4(\mathrm{p}<0.001)$ [9].

Six $(7.22 \%)$ patients with SBP $<130 \mathrm{mmHg}$ developed preeclampsia whereas every patients with SBP more than $150 \mathrm{mmHg}$ developed preeclampsia $(\mathrm{p}<0.05)$. Almost similar results were reported by other study [9].

Out of 100 patients, $35 \%$ developed diastolic notch at 11-14 weeks of gestation, of that 15 (42.8\%) developed preeclampsia $(\mathrm{p}=0.002)$, which is similar to Gupta et al who reported $31.42 \%$ patients developing preeclampsia in presence of diastolic notching [8]. This is less as compared to Myatt et al wherein $15 \%$ cases had presence of diastolic notching at $<21$ weeks of gestation and $18 \%$ of these patients developed preeclampsia [14]. Present study, as 35\% had diastolic notching at $11-14$ weeks of pregnancy out of that $15(42.85 \%)$ developed preeclampsia, hence sensitivity of diastolic notching is $68 \%$, specificity is $74 \%$, positive (PPV) and negative predictive values (NPV) were $42.85 \%$ and $89.23 \%$ respectively in prediction of preeclampsia. 
In present study, the mean PI was 1.179 at $11-14$ weeks of gestation. But in patients with preeclampsia mean PI value at 11-14 weeks was 1.44 which was significant compared to non-preeclamptic women $(\mathrm{p}<0.001)$. This shows that PI can help in prediction of preeclampsia when combined with uterine artery notching similar to Gomez et al [7]. Myatt et al also found significant association between PI and development of preeclampsia, mean PI was 1.10 in women with preeclampsia while it was 0.98 in women without preeclampsia $(p=0.02)$ [14]. Out of 100 patients, $15 \%$ had PI of $>1.71$ at $11-14$ weeks of pregnancy out of that $12(80 \%)$ developed preeclampsia hence sensitivity of PI is $54.54 \%$ and specificity is $96.15 \%$, PPV $85 \%$, NPV $88 \%$ in prediction of preeclampsia.

Rattanapuntamamnee et al determined the uterine artery pulsatility index to describe the characteristic of uterine artery doppler velocimetry in pregnant Thai patients at 11-13 gestational weeks. They found that when segregated for gestational age, uterine artery PI was $1.78 \pm 0.41$ at 11 weeks, $1.72 \pm 0.41$ at 12 weeks and $1.66 \pm 0.43$ at 13 weeks gestation. The uterine artery PI was $1.84 \pm 0.37$ with the presence of notching and was $1.59 \pm 0.43$ without notching. The uterine artery notching was present in $19.3 \%, 16 \%$ and $18 \%$ of the patients at $11,12,13$ weeks respectively. This group found that even in first trimester uterine artery diastolic notch in combination with other parameters seems to be a good test for prediction of obstetric vasculopathies especially pregnancy-induced hypertension $(\mathrm{PIH})$ and intrauterine growth restriction (IUGR) [5].

Pilalis et al in their study showed that uterine artery doppler assessed for PI and presence of diastolic notch at 11-14 weeks of gestation identified one third of subjects with severe early onset preeclampsia [15].

Similarly when presence of uterine artery diastolic notch was considered together with pulsatility index $>1.71$, the sensitivity was found to be $75 \%$, specificity $60.8 \%$, PPV 57.14\%, NPV 67.78\%.

As Desai $P$ mentioned in a review article that disappearance of uterine artery diastolic notch in combination with other parameters is a good test for predicting vasculopathies particularly PIH and IUGR in first trimester, findings of our study also shows that combining PI with uterine artery notching is helpful in predicting preeclampsia [4].

\section{Conclusion}

From the present study we can conclude that use of uterine artery colour doppler for presence of diastolic notch and measurement of PI value at 11-14 weeks of gestation is a helpful and non-invasive tool in prediction of preeclampsia at term in normal pregnancies. The presence of diastolic notch and PI value $>1.71$ at $11-14$ weeks of gestation serves as a good predictor of preeclampsia at term in pregnancies with no other associated risk factors. Hence all pregnancies should be screened with uterine artery doppler at 11-14 weeks of gestation for identifying cases that could develop preeclampsia and hence introduce early interventions to prevent and reduce the severity of the same.

\section{Funding: Nil \\ Conflict of interest: None. \\ Permission of IRB: Yes}

\section{References}

1. Sheppard BL, Bonnar J. An ultrastructural study of utero-placental spiral arteries in hypertensive and normotensive pregnancy and fetal growth retardation. Br J Obstet Gynaecol 1981; 88(7):695-05.

2. Harrington K, Cooper D, Lees C, Hecher K, Campbell S. Doppler ultrasound of the uterine arteries: the importance of bilateral notching in the prediction of pre-eclampsia, placental abruption or delivery of a small-for-gestational-age baby. Ultrasound Obstet Gynecol. 1996 Mar;7(3):182-8.

3. Vainio M, Kujansuu E, Iso-Mustajärvi M, Mäenpää J. Low dose acetylsalicylic acid in prevention of pregnancy-induced hypertension and intrauterine growth retardation in women with bilateral uterine artery notches. International Journal of Obstetrics and Gynaecology 2002; 109(2):161-7.

4. Desai P. Predicting Obstetric Vasculopathies through Study Diastolic notch and Other Indices of Resistance to Blood Flow in Uterine Artery. Int J Infertility Fetal Med 2013; 4 (1):24-30.

5. Rattanapuntamanee O, Uerpairojkit B. Reference range and characteristic of uterine artery Doppler in pregnant Thai women at 11-13(+6) gestational weeks. J Med Assoc Thai. 2011 Jun;94(6):644-8. 
6. Martinez RC, Savchev S, Lemini MC, Mendez A, Gratacos E, Figueras F. Clinical utility of third-trimester uterine artery Doppler in the prediction of brain hemodynamic deteriorationand adverse perinatal outcome in small-for-gestational-age Fetuses. Ultrasound Obstet Gynecol 2015; 45 (3): 273-8.

7. Gómez O, Martínez JM, Figueras F, Del Río M, Borobio V, Puerto B et al. Uterine artery Doppler at 11-14 weeks of gestation to screen for hypertensive disorders and associated complications in an unselected population. Ultrasound Obstet Gynecol 2005; 26(5):490-4.

8. Gupta S, Kumar GP, Preeti B, Anshu K. Transvaginal Doppler of uteroplacental circulation in early prediction of pre-eclampsia by observing bilateral uterine artery notch and resistance index at 12-16 weeks of gestation. J Obstet Gynecol India 2009; 59 (6):541-6.

9. Kiondo P, Wamuyu-Maina G, Bimenya GS, Tumwesigye NM, Wandabwa J, Okong P. Risk factors for pre-eclampsia in Mulago Hospital, Kampala, Uganda. Trop Med Int Health. 2012 Apr;17(4):480-7. doi: 10.1111/j.1365-3156.2011.02926.x. Epub 2011 Dec 13 .

10. Dinglas C, Lardner D, Homchaudhur A , Kelly C, Briggs C, Passafaro M. Relationship of Reported Clinical Features of Pre-eclampsia and Postpartum Haemorrhage to Demographic and other Variables. West African Journal of Medicine. 2011; 30(2): 84-8.
11. Mangal A, Kumar V, Panesar S, Talwar R, Raut D, Singh S. Updated BG Prasad socioeconomic classification, 2014: a commentary. Indian J Public Health. 2015 Jan-Mar;59(1):42-4. doi: 10.4103/0019$557 X .152859$.

12. Silva LM, Coolman M, Steegers EA, Jaddoe VW, Moll HA, Hofman A, Mackenbach JP, Raat H. Low socioeconomic status is a risk factor for preeclampsia: the Generation $\mathrm{R}$ Study. J Hypertens. 2008 Jun;26(6):1200-8. doi: 10.1097/HJH.0b013e3282fcc36e.

13. Long PA, Abell DA, Beischer NA. Parity and preeclampsia. Aust N Z J Obstet Gynaecol. 1979 Nov;19(4):203-6.

14. Myatt L, Clifton RG, Roberts JM, Spong CY, Hauth JC, Varner MW, Wapner RJ, Thorp JM Jr, Mercer BM, Grobman WA, Ramin SM, Carpenter MW, Samuels P,Sciscione A, Harper M, Tolosa JE, Saade G, Sorokin Y, Anderson GD; Eunice Kennedy Shriver National Institute of Child Health and Human Development (NICHD) Maternal-Fetal Medicine Units Network (MFMU). The utility of uterine artery Doppler velocimetry in prediction of preeclampsia in a low-risk population. Obstet Gynecol. 2012 Oct;120(4):815-22.

15. Pilalis A, Souka AP, Antsaklis P, Daskalakis G, Papantoniou N, Mesogitis S, Antsaklis A. Screening for pre-eclampsia and fetal growth restriction by uterine artery Doppler and PAPP-A at 11-14 weeks' gestation. Ultrasound Obstet Gynecol. 2007 Feb;29(2):135-40.

\section{How to cite this article?}

Bindal J, Chugh N, Utility of uterine artery Doppler and pulsatility index at 11-14 weeks of normal pregnancy in prediction of preeclampsia in third trimester : Int J Med Res Rev 2016;4(3):432-436. doi: 10.17511/ijmrr.2016.i03.26. 